\title{
Immunogenic senescence sensitizes lung cancer to LUNX-targeting therapy
}

\author{
Defeng Jiao ${ }^{1,2} \cdot$ Xiaohu Zheng ${ }^{1,2} \cdot$ Xianghui Du$^{1,2} \cdot$ Dong Wang ${ }^{1,2} \cdot$ Ziming Hu$^{1,2} \cdot$ Rui Sun $^{1,2} \cdot$ Zhigang Tian $^{1,2}$. \\ Binqing $\mathrm{Fu}^{1,2} \cdot$ Haiming $\mathrm{Wei}^{1,2}$
}

Received: 2 June 2021 / Accepted: 30 September 2021 / Published online: 21 October 2021

(c) The Author(s) 2021

\begin{abstract}
The higher immunogenicity of tumors usually predicts favorable therapeutic responses. Tumor antigens dominate the immunogenic character within tumors. We investigated if there was a targetable tumor antigen during immunogenic chemotherapy within lung cancer. Chemotherapy-induced immunogenic senescence was demonstrated using a multi-marker, three-step workflow, and RNA-sequencing data. The ability of anti-lung-specific X protein (LUNX) antibody to suppress the survival of senescent lung cancer cells was evaluated in vitro and in vivo using real-time cytotoxicity analysis and xenograft mouse models, respectively. The induction of cellular senescence by immunogenic chemotherapy boosted cell-surface shuttling of LUNX and enhanced the immunogenic features of senescent tumor cells, which sensitized lung cancer cells to antiLUNX antibody-mediated therapy and contributed to tumor suppression. The immunogenic senescence-mediated antitumor response was triggered by the direct action of antibody on tumor cells, strengthened by natural-killer cells through an antibody-dependent cell-mediated cytotoxicity response, and ultimately, led to tumor control. Our findings suggest that LUNX is a lung cancer targetable-immunogenic antigen. The proportion of lung cancers responding to LUNX-targeting therapy could be expanded substantially by immunogenic chemotherapy that induces senescence-associated translocation of LUNX to the plasma membrane.
\end{abstract}

Keywords Immunogenic chemotherapy $\cdot$ Senescence $\cdot$ LUNX $\cdot$ Antibody $\cdot$ Lung cancer

\section{Introduction}

Recent studies investigating tumor immunogenicity have, in general, focused on cell-intrinsic damage-associated molecular patterns, such as the exposure of calreticulin on the cell surface, and the release of adenosine triphosphate

Xiaohu Zheng

ustczxh@ustc.edu.cn

Binqing $\mathrm{Fu}$

fbq@ustc.edu.cn

$\triangle$ Haiming Wei

ustcwhm@ustc.edu.cn

1 Division of Molecular Medicine, Hefei National Laboratory for Physical Sciences at Microscale, The CAS Key Laboratory of Innate Immunity and Chronic Disease, School of Life Sciences, University of Science and Technology of China, Hefei 230027, China

2 Institute of Immunology, University of Science and Technology of China, Hefei 230027, China and high-mobility group box 1 into the extracellular environment [17, 25]. The aberrant location of these molecules exhibits strong adjuvanticity and alerts the immune system to "a dangerous state" being present $[30,38]$. However, these molecules alone are not sufficient to initiate an adaptive immune response, and they are usually normal cellular components carrying out crucial metabolism or structural functions [16, 33]. Hence, none of these molecules is a truly specific immunogenic tumor antigen. As immunogenicity of tumors depends on both adjuvanticity and antigenicity, defining tumor-specific immunogenic antigens during immunogenic chemotherapy can be a very interesting and rational task.

The lung-specific X protein (LUNX) gene (also known as BPIFA1, SPLUNC1, and PLUNC) was isolated first by Kyoko and colleagues [22]. They established a LUNX-based real-time reverse transcription-quantitative polymerase chain reaction (RT-qPCR) assay for detection of micro-metastases in the lymph nodes of non-small-cell lung cancer (NSCLC) patients. It has also been reported that LUNX protein levels 
in normal small airways are relatively low, and LUNX staining is absent in normal peripheral lung tissue [3, 5]. A moderate increase in LUNX expression in nasal secretions and sputum has been detected to occur in inflammatory airway diseases such as allergic rhinitis and chronic obstructive pulmonary disease $[13,27]$. Subsequent reports have suggested that LUNX is undetectable in the normal adrenal gland, brain, liver, kidney, and peripheral lung tissues in humans $[4,5,22]$. Building on such work, our previous study proposed LUNX mRNA and LUNX protein to be a specific diagnostic marker and a novel candidate therapeutic target for NSCLC, respectively, because no detectable expression of LUNX has been found in other tumors such as hepatocellular carcinoma or ovarian cancer [10, 42]. LUNX overexpression promotes the migration and proliferation of lung cancer cells and, in general, predicts a poor prognosis for NSCLC patients. Targeting LUNX via anti-LUNX antibody or LUNX-chimeric antigen receptor (CAR) T cells has been shown to suppress the growth and metastasis of xenografts and patient-derived xenografts in a mouse model of NSCLC [20, 42]. Mechanismly, upon binding to the surface LUNX, the anti-LUNX antibody reduces LUNX protein levels via antibody-mediated endocytosis and degradation which in turn represses downstream signaling responsible for tumor cell proliferation and survival [42]. Therefore, LUNX might represent a promising targetable antigen for NSCLC.

"Cellular senescence" is a stable growth-arresting cellular state triggered by nonlethal stress, such as exposure to oxidative damage or genotoxic agents, overexpression of oncogenes, or mitochondrial dysfunction $[2,18]$. Alessandra and colleagues showed that myeloma cells treated with therapeutic agents such as melphalan up-regulated the expression of DNAX accessory molecule-1 and natural killer group 2D (NKG2D) ligands and exhibited a senescent-like phenotype [39]. Other reports have also suggested that senescent cells could secrete a wide range of senescence-associated secretory phenotypes (SASPs), which could modulate the immune response and have direct effects on tumor progression $[12,15]$.

Here, we report that immunogenic chemotherapy-treated lung cancer cells exhibited an immunogenic senescence phenotype and had high expression of LUNX on their plasma membrane, which served as a targetable immunogenic antigen. Targeting LUNX on cells membranes via anti-LUNX antibody could suppress the growth of lung cancer cells significantly in vitro and in vivo. Our study suggests that: (1) LUNX is a lung cancer-targetable tumor antigen during immunogenic senescence; (2) combining anti-LUNX antibody with immunogenic drugs that can induce senescenceassociated translocation of LUNX to the plasma membrane might offer a new strategy to treat NSCLC.

\section{Materials and methods}

\section{Mice}

Experimental procedures involving animals were conducted in accordance with the National Guidelines for Animal Usage in Research (China). Permission to undertake animal studies was obtained from the Ethics Committee of the University of Science \& Technology of China (Hefei, China).

Female BALB/cJGpt-Foxn1 ${ }^{\text {nu}} /$ Gpt and NOD/ShiLtJGptPrkdc ${ }^{\mathrm{em} 26 \mathrm{Cd} 52} \mathrm{Il} 2 \mathrm{rg}^{\mathrm{em} 26 \mathrm{Cd} 22} / \mathrm{Gpt}$ mice (aged 6 weeks) were purchased from GemPharmatech (Nanjing, China). Mice were maintained under specific pathogen-free conditions.

\section{Cell lines}

A549 cells and NCI-H292 cell lines were obtained from the Shanghai Cell Bank (Chinese Academy of Sciences, Shanghai, China). They were passaged by our research team for $<6$ months after receipt or revival. Cells were cultured in complete RPMI medium 1640 (HyClone, Logan, UT, USA) with $10 \%$ fetal bovine serum (Gibco, Grand Island, NY, USA) plus $1 \%$ streptomycin and penicillin in an atmosphere of $5 \% \mathrm{CO}_{2}$ at $37{ }^{\circ} \mathrm{C}$. The average diameter of A549 cells and NCI-H292 cells was measured using the Countstar® cell-analysis system (ALIT Life Sciences, Shanghai, China) after cells had been trypsinized.

\section{Antibody production}

The anti-LUNX antibody was introduced in our previous work [42] and humanized to replace the Fc region with the human IgG1 Fc region. Briefly, S-35-8 (IgG2a-k) LUNX hybridoma was raised against a His-tagged LUNX protein and screened by ELISA. The hybridoma was cultured in RPMI-1640 medium. The S-35-8 anti-LUNX antibody was purified by protein A affinity chromatography (GE Healthcare Bio-Sciences AB).

\section{Immunofluorescence}

A549 cells and NCI-H292 cells were plated at $1 \times 10^{5}$ onto 15-mm glass-bottom culture dishes overnight. They were treated with the indicated concentration of mitoxantrone or vehicle for $48 \mathrm{~h}$. After removal of culture supernatants, cells were washed twice with cold phosphate-buffered saline (PBS) and blocked for $30 \mathrm{~min}$ at room temperature (RT) with $1 \%$ bovine serum albumin plus $5 \%$ normal goat serum. Primary antibody and secondary antibody were added for $60 \mathrm{~min}$ at $4{ }^{\circ} \mathrm{C}$, followed by fixation with $4 \%$ paraformaldehyde for 15 min and staining with 4',6-Diamidino-2-phenylindole dihydrochloride for $7 \mathrm{~min}$ at RT. Next, cells were 
washed thrice with cold PBS and visualized using a confocal laser scanning microscope (LSM 880; Zeiss, Oberkochen, Germany). For intracellular staining of HP1 $\gamma$, cells were permeabilized with $0.1 \%$ Triton-X for 10 min at RT after staining cell surface expression of LUNX.

\section{Flow cytometry}

A549 cells and NCI-H292 cells were trypsinized and collected by centrifugation $(125 \times g, 5 \mathrm{~min}, \mathrm{RT})$. After resuspension in $100 \mu \mathrm{L}$ of PBS containing the defined antibody, cells were incubated for $30 \mathrm{~min}$ at $4{ }^{\circ} \mathrm{C}$. Then, the cells were washed twice with cold PBS and investigated by flow cytometry (LSRII; BD Biosciences, Franklin Lakes, NJ, USA).

\section{RT-qPCR}

Total RNA was prepared using TRIzol® Reagent (Invitrogen, Carlsbad, CA, USA) and reverse-transcribed into complementary (c) DNA using a random primer (Invitrogen). The resulting cDNA was analyzed for the expression of LUNX, UL16-binding protein (ULBP) 1-6, MIC-A, and MIC-B. Real-time PCR was carried out in triplicate using SYBR Green, and $\beta$-actin served as an endogenous normalization control.

\section{Senescence-associated $\beta$-galactosidase staining}

A549 cells and NCI-H292 cells were plated at $1 \times 10^{5}$ in six-well culture plates overnight. They were treated with the indicated concentration of mitoxantrone or vehicle for $48 \mathrm{~h}$. After removal of culture supernatants, cells were washed twice with cold PBS and fixed for $15 \mathrm{~min}$ at RT. Then, cells were incubated with fresh senescence-associated $\beta$-galactosidase (SA- $\beta$-gal) staining solution (Beyotime Institute of Technology, Beijing, China) overnight without $\mathrm{CO}_{2}$ at $37^{\circ} \mathrm{C}$. If needed, cells were trypsinized moderately to show the edge of each cell before fixation. Images were acquired using a microscope (IX-81; Olympus, Tokyo, Japan).

\section{Western blotting}

Lysates of whole A549 cells and NCI-H292 cells were prepared using RIPA Lysis and Extraction Buffer (Thermo Scientific, Waltham, MA, USA) supplemented with Halt Protease Inhibitor Cocktail (Thermo Scientific). After centrifugation $\left(14,000 \times g, 10 \mathrm{~min}, 4{ }^{\circ} \mathrm{C}\right)$, supernatants were collected for sodium dodecyl sulfate-polyacrylamide gel electrophoresis. Then, proteins were transferred to polyvinylidene difluoride (PVDF) membranes and blocked with QuickBlock ${ }^{\mathrm{TM}}$ Western for 15 min at RT. PVDF membranes were incubated with primary antibodies overnight at $4{ }^{\circ} \mathrm{C}$ and then incubated with horseradish peroxidase-conjugated secondary antibodies for $1 \mathrm{~h}$ at RT. Protein bands were developed by chemiluminescence autoradiography.

\section{Enzyme-linked immunosorbent assay (ELISA)}

Measurement of the level of interleukin (IL)-6 and IL-8 in culture supernatants was carried out using ELISAs according to manufacturer instructions. Briefly, culture supernatants were added to pre-coated 96-well plates and incubated with detection antibody for $60 \mathrm{~min}$ at RT. Then, the plates were washed thrice and incubated with streptavidin-horseradish peroxidase for $20 \mathrm{~min}$ at RT. 3,3',5,5'-Tetramethylbenzidine substrate solution was added. The reaction was stopped after 2-5 min followed by measurement of absorbance in 96-well plates at $450 \mathrm{~nm}$.

\section{Real-time cytotoxicity assays}

The cytotoxicity assays of A549 cells and NCI-H292 cells were monitored using the xCELLigence Real-Time Cell Analyzer-Multiple Plate system (Roche Applied Science, Basel, Switzerland). Briefly, normal cells or senescent A549 cells and NCI-H292 cells were plated at $1 \times 10^{4}$ in 16-well $E$-plates for $\sim 20 \mathrm{~h}$ until the Cell Index reached 1. Then, freshly isolated natural killer (NK) cells from human peripheral blood mononuclear cells (PBMCs) or anti-LUNX antibody were added to the $E$ plate at a defined effect/target ratio or concentration, respectively. For real-time monitoring, the Cell Index was read automatically every $15 \mathrm{~min}$.

\section{Isolation of NK cells from human PBMCs}

Human PBNCs were isolated using Ficoll density gradients. NK cells were purified by a Magnetic-Activated Cell Sorter kit (Miltenyi Biotec, Bergisch Gladbach, Germany). The purity of NK cells for each assay was $>90 \%$.

\section{In vivo experiments}

Female nude or NCG mice were used to establish subcutaneous and metastatic lung cancer xenografts to assess the antitumor capacity of a combination of chemotherapy and anti-LUNX antibody. For the subcutaneous xenograft model, $2 \times 10^{6}$ A549 cells were injected (s.c.) into the axilla and treatment started once the tumors were palpable. The tumor volume was calculated as (width ${ }^{2} \times$ length) $/ 2$. In the metastatic xenograft model, $5 \times 10^{5}$ A549-luciferase cells were transplanted (i.v.) into mice. After $24 \mathrm{~h}$, mice were assigned randomly to groups and treated as indicated. Tumor metastasis was analyzed by live body images of mice. 


\section{Statistical analyses}

Statistical significance was determined using Prism 8.0 (GraphPad, San Diego, CA, USA). Two-tailed unpaired Student's $t$-tests between two groups and one-way analysis of variance across multiple groups were used to determine significance. A one-sided Fisher's exact test was utilized to estimate the correlation between the expression of LUNX and Heterochromatin protein 1 homolog gamma (HP1 $\gamma$ ). Data represent the mean \pm SD. $P<0.05$ was considered significant.

\section{Results}

\section{Immunogenic chemotherapy induces translocation of LUNX to the plasma membrane}

Immunogenic tumors exhibit a better prognosis than nonimmunogenic tumors [36]. Hence, we examined the ability of several Food and Drug Administration (FDA)-approved chemotherapeutic agents to induce cell-surface shuttling of LUNX, which we proposed previously to be a promising tumor antigen in NSCLC [32, 42]. The first-line chemotherapy agent cisplatin slightly stimulated the translocation of LUNX to the cell surface at the maximum dose tested (Figure S1A, B). Nevertheless, gemcitabine treatment stimulated cell-surface translocation of LUNX at all doses tested (Figure S1C, D). Furthermore, the anthracycline mitoxantrone, which can show an immunogenic effect [30], strongly increased the LUNX expression on the surface of A549 cells and NCI-H292 cells after $48 \mathrm{~h}$ of treatment, especially at $50 \mathrm{nM}$ and $100 \mathrm{nM}$ (Fig. 1A-D). To exclude the possibility that the increased expression of LUNX on the cell surface was due to transcriptional up-regulation of LUNX mRNA, we evaluated LUNX expression at the mRNA level (Figure $\mathrm{S} 1 \mathrm{E}-\mathrm{G})$. There was no significant difference in mRNA expression between all doses tested for mitoxantrone, cisplatin, or gemcitabine. Total protein level expression of LUNX also exhibited no significant change after mitoxantrone treatment (Figure S1H). Intriguingly, we observed a significant increase in the cell volume upon immunofluorescence staining (Fig. 1A, C) and measured by average diameter of both cell types (Fig. 1E, F). Flow cytometry revealed not only the enlarged cell volume (data not shown) but increased cytoplasmic granularity as demonstrated by a higher side scatter-A strength (Fig. 1G). Taken together, these data suggested that immunogenic chemotherapy strongly stimulated the translocation of LUNX to the plasma membrane and that this phenomenon might be related to a significant change in cell morphology.

\section{Cellular senescence correlates with LUNX shuttling}

We wished to determine the mechanism by which mitoxantrone treatment promoted LUNX translocation and induced a flattened, enlarged morphology. Hence, we focused on investigating the significant change in cell morphology after mitoxantrone treatment [14]. As reported previously, mitoxantrone treatment leads to the immunogenic cell death of tumor cells, which is a bona fide apoptotic form of cell death, but without the morphological change mentioned above $[12,40]$. Seifrtova and colleagues reported that exposure of dental pulp stem cells and human dermal fibroblasts to mitoxantrone resulted in cellular senescence that was characterized by the typical morphological changes we mentioned above [37]. Hence, we first analyzed the expression of SA- $\beta$-gal in tumor cells after mitoxantrone treatment, which serves as the most classical marker of senescence [18]. A549 cells and NCI-H292 cells showed a sharp increase in SA- $\beta$-gal activity, with positive cells exhibiting a flattened, enlarged morphology (Fig. 2A-D). Moreover, these cells maintained and increased the expression of SA- $\beta$-gal 7 days after drug withdrawal (Figure S2A, $B)$. Analyses of protein expression confirmed the dramatic reduction of LMNB1 expression (Fig. 2E), which is another marker of senescence [18]. The P53-P21 (also known as cyclin-dependent kinase inhibitor 1) pathway and retinoblastoma-associated protein pathway are known to be "master regulators" of the senescence program [11]. Mitoxantrone treatment significantly stimulated the expression of P53 and its downstream target $\mathrm{P} 21$. The protein expression of $\mathrm{pRB}$ decreased slightly (Fig. 2E). SASP components, including proinflammatory and immune-modulatory cytokines such as IL-6 and IL-8, are also key features of senescence [8]. By measuring the expression of IL- 6 protein and IL- 8 protein in the cell-culture supernatants of mitoxantrone-treated A549 cells and NCI-H292 cells, we discovered a significant 2-6 fold increase in both cell lines tested when compared with that in a non-treated control (Fig. 2F, G). Besides, western blotting detecting the cleaved caspase 3 in A549 and NCI-H292 cells treated with low dose of mitoxantrone also showed no obvious apoptosis (Fig S2C and D). FACS data also revealed that only a few portion of cells died after low dose of mitoxantrone treatment in both A549 and NCIH292 cells as showed by annexin V and 7AAD staining (Fig S2E and F). Our data indicated that the low dose of mitoxantrone treatment did not induce apoptosis in A549 
A

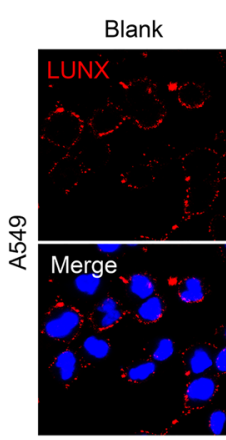

C

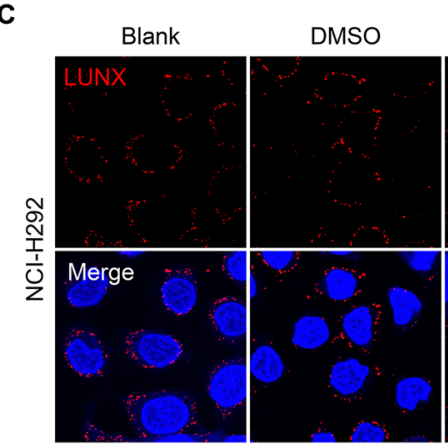

E
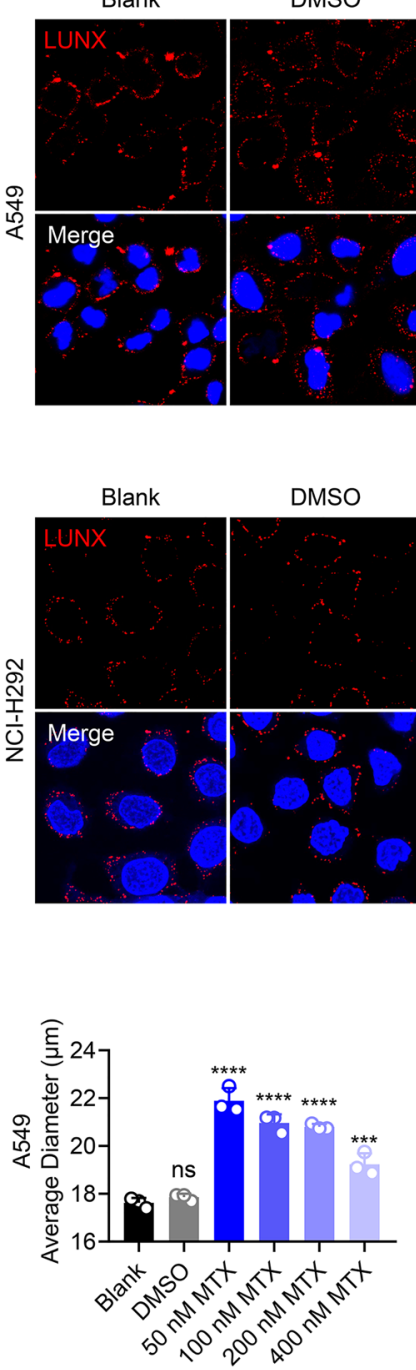

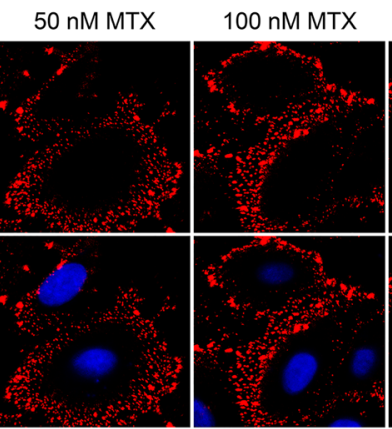

200 nM MTX
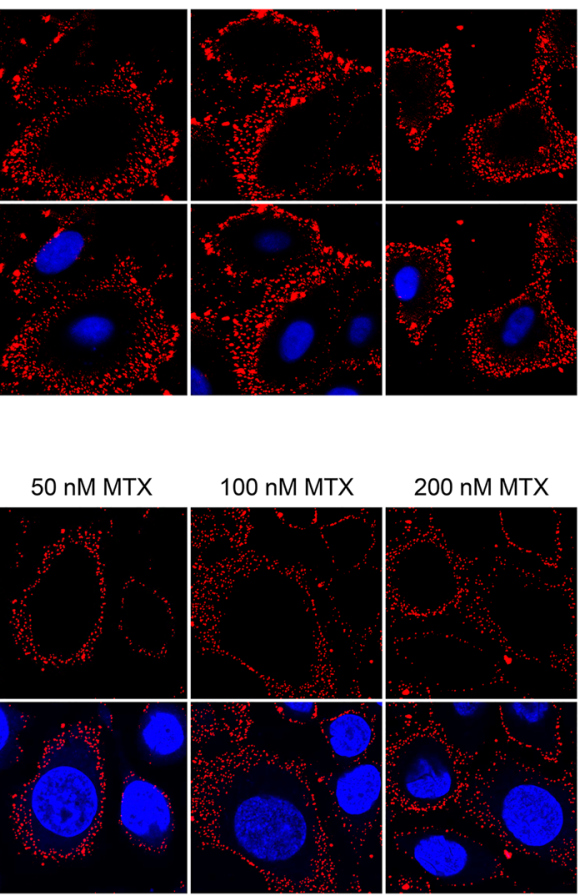

$\mathbf{F}$

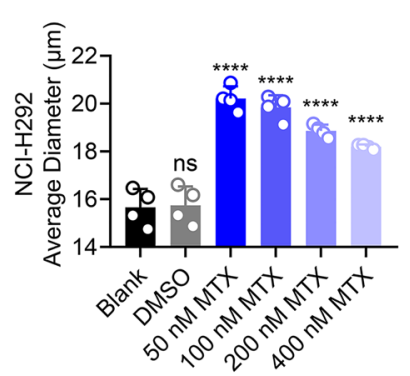

$400 \mathrm{nM}$ MTX

B

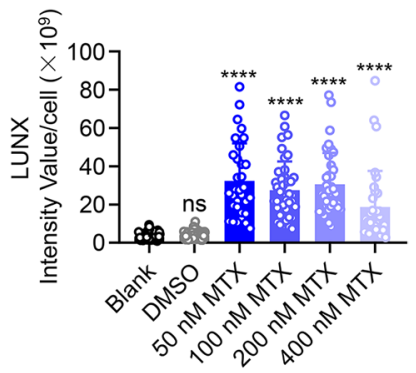

D

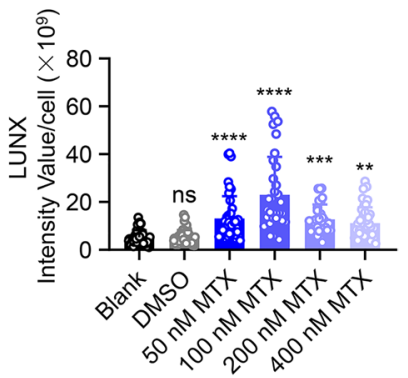

G

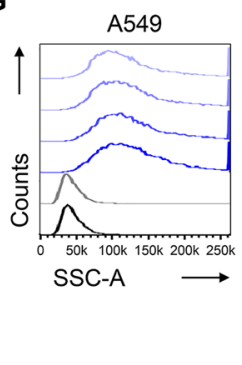

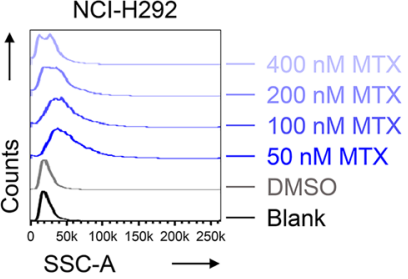

Fig. 1 Cell-surface shuttling of LUNX after immunogenic chemotherapy (A-D) Surface exposure of LUNX was determined by immunofluorescence $48 \mathrm{~h}$ after treatment with the indicated concentration of mitoxantrone (MTX). Representative images are shown for A549 (A) and NCI-H292(C). Scale bar $=20 \mu \mathrm{m}$. We calculated the inten- sity value for each A549 cell (B) and NCI-H292 cell (D). Anti-LUNX concentration $=200 \mu \mathrm{g} / \mathrm{mL}$. (E, F) The average diameter of A549 (E) and NCI-H292 (F) $48 \mathrm{~h}$ after treatment with mitoxantrone. ( $n=3-4$ replicates). (G) Flow cytometry for side-scatter detection of A549 cells and NCI-H292 cells $48 \mathrm{~h}$ after mitoxantrone treatment and NCI-H292 cells. These results suggested that mitoxantrone treatment induced A549 cells and NCI-H292 cells to undergo senescence.

We wished to test directly whether cell-surface shuttling of LUNX was associated with cellular senescence induced by mitoxantrone. Hence, we co-stained LUNX with HP1 $\gamma$, expression of which has also been shown to increase during senescence [29]. Mitoxantrone treatment led to a significant increase in the expression of LUNX and HP1 $\gamma$ (Fig. 3A, B). Furthermore, there was a strong correlation between the surface exposure of LUNX and the nuclear expression of HP1 $\gamma$ (Fig. 3B, D). These data provided evidence that mitoxantrone treatment-induced A549 cells and NCI-H292 cells to undergo senescence, which promoted the translocation of LUNX to the plasma membrane.

\section{Senescent cells exhibit an "immunogenic signature"}

We identified that LUNX translocation correlated strongly with the senescence of tumor cells induced by mitoxantrone treatment. Next, we aimed to evaluate the exact differences between normal cells and senescent tumor cells by RNA sequencing of normal (dimethyl sulfoxide-treated) and 

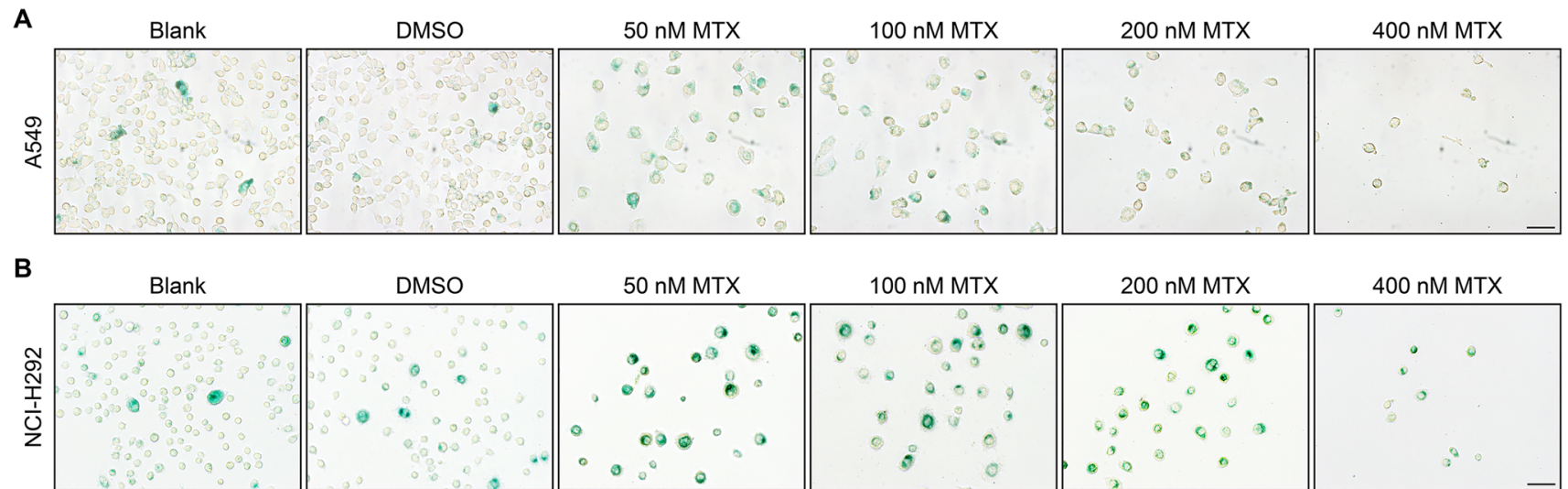

C

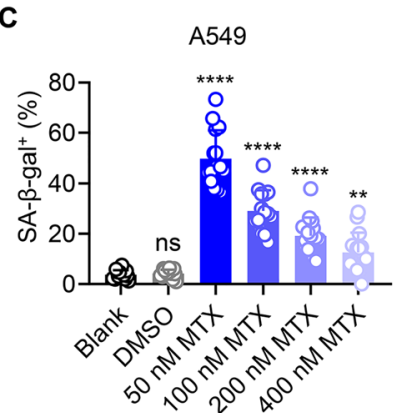

$\mathbf{F}$

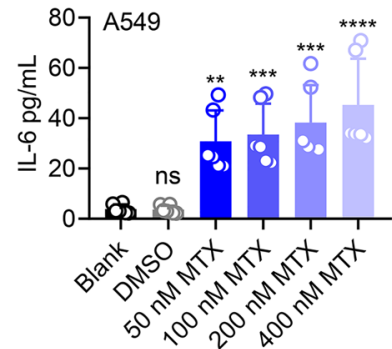

(1)
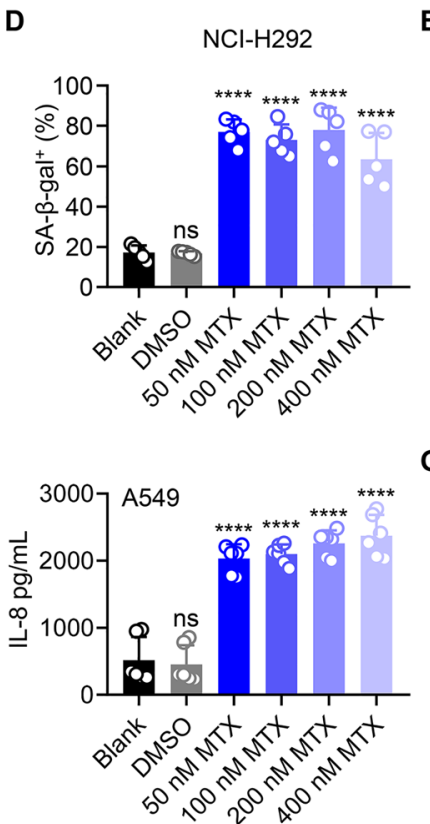

Fig. 2 Induction of cellular senescence A-D A549 cells and NCIH292 cells were assayed for SA-b-gal activity $48 \mathrm{~h}$ after treatment with the appropriate concentration of mitoxantrone. Representative images are shown for A549 cells (A) and NCI-H292 cells (C). Scale bar $=50 \mu \mathrm{m}$. We calculated the ratio of SA- $\beta$-gal-positive A549 cells (B) and SA- $\beta$-gal-positive NCI-H292 cells (D). E Lysates of whole

senescent (mitoxantrone-treated) A549 cells and NCI-H292 cells. Collectively, up-regulation of expression of 2677 unique transcripts and down-regulation of 1869 transcripts was evident in the transcriptional profiles of senescent A549 cells compared to normal A549 cells (Fig. 4A). Nevertheless, there were far fewer and less significant transcripts in senescent NCI-H292 cells compared with those in normal NCI-H292 cells, including only 793 up-regulated transcripts and 512 down-regulated transcripts (Fig. 4B). The expression of transcripts encoding the cell-surface markers of
E
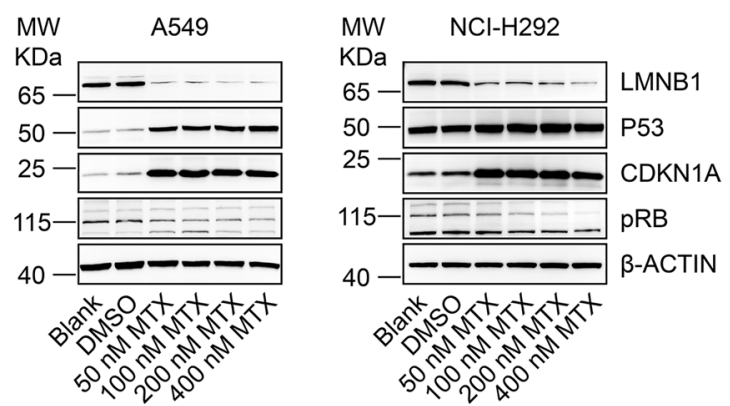

G
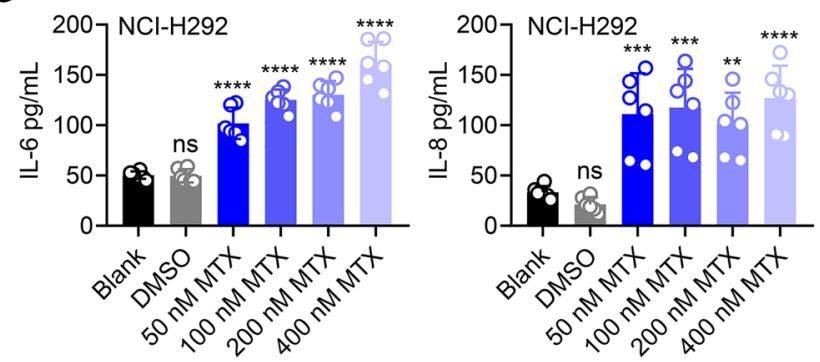

A549 cells and NCI-H292 cells were collected $48 \mathrm{~h}$ after treatment with mitoxantrone and analyzed by western blotting using the indicated antibodies. Actin is shown as a loading control. (F, G) In vitro release of IL- 6 and IL- 8 by A549 cells (F) and NCI-H292 cells (G) in response to mitoxantrone as determined by ELISA

activation (e.g., Tumor necrosis factor ligand superfamily member 14 (TNFSF14) and cluster of differentiation-70) and inflammatory cytokines (e.g., IL-1 $\beta$ and CXCL1) was also up-regulated (Fig. 4A, B) [19, 23]. The elevated expression of these genes indicated that senescent tumor cells might recruit and activate immune cells more potentially.

Analyses of mRNA transcripts using the Kyoto Encyclopedia of Genes and Genomes revealed that genes were categorized in different signal-transduction pathways between A549 cells and NCI-H292 cells (Figure S3A, B), but the "Cellular senescence" pathway, "Cellular cycle" pathway, and "P53 signaling" pathway were enriched in both. We undertook gene set enrichment analysis of canonical 
A
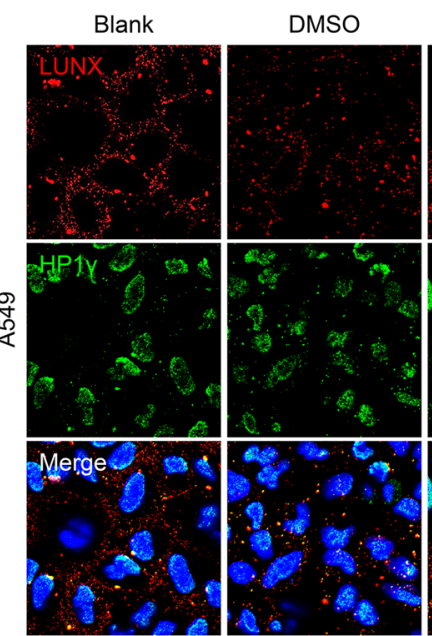

50 nM MTX

$100 \mathrm{nM}$ MTX
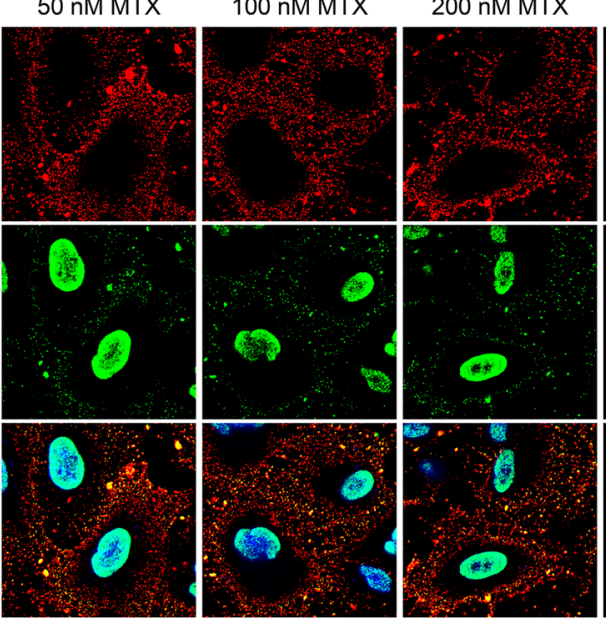

$400 \mathrm{nM}$ MTX

C
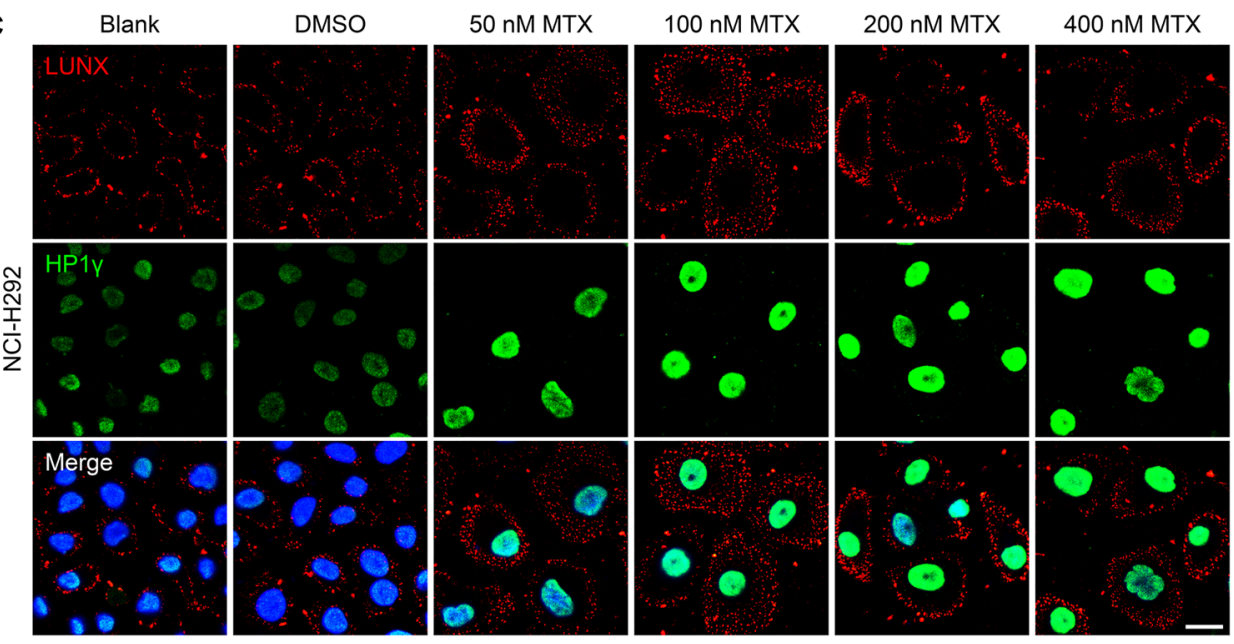

D
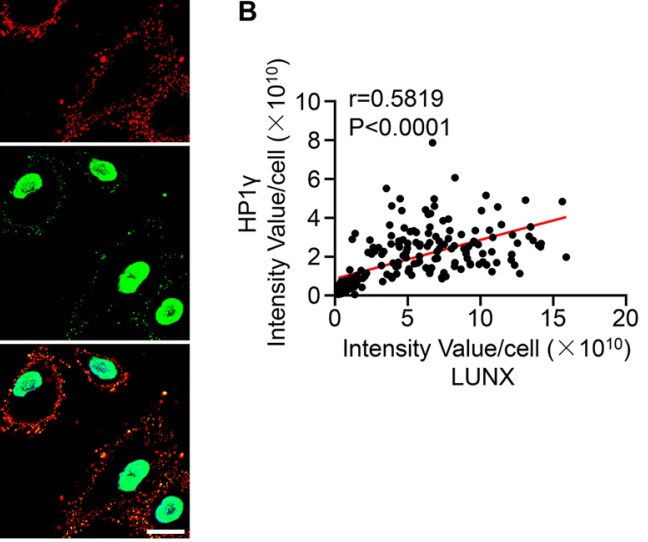

LUNX

Fig. 3 Cellular senescence correlates with LUNX shuttling (A-D) Confocal laser scanning microscopy showing the expression of LUNX (red) and HP1 $\gamma$ (green) in A549 cells (A) and NCI-H292 cells

pathways curated by the MSig database. Comparison of the transcriptomes of senescent versus normal A549 cells (Figure S3C) or senescent versus normal NCI-H292 cells (Figure S3D) showed that the G2M checkpoint, E2F targets, and Myc targeting pathways were enriched in normal cells but not in senescent cells. Hence, cell-cycle arrest and proliferation of stasis in senescent A549 cells and NCI-H292 cells occurred, which confirmed the effect of mitoxantroneinduced senescence [9].

Intriguingly, in senescent A549 cells, the "Activation of the Innate Immune Response" pathway was enriched significantly, as was the "Natural Killer Cell-Mediated Cytotoxicity" pathway, which suggested that senescent tumor cells might activate an NK cell-mediated response (Fig. 4C).
(C). Scale bar $=20 \mu \mathrm{m}$. Anti-LUNX concentration $=200 \mu \mathrm{g} / \mathrm{mL}$. Correlation between exposure to LUNX of the cell surface and nuclear expression of HP1 $\gamma$ in A549 cells (B) and NCI-H292 cells (D)

Senescent NCI-H292 cells exhibited similar signature (Figures S3D). Further evidence for the translocation of LUNX was the observation that the "Antigen Processing And Presentation" pathway and "Protein Secretion" pathway were also enriched in A549 cells and NCI-H292 cells, respectively (Fig. 4C, S3D). Heatmap analyses revealed expression of pivotal senescent genes (left column) and immunogenic genes enriched in TNF pathway (middle column) and natural killer cell-mediated cytotoxicity pathway (right column) such as IL-6, IL-8, CDKN1A, ICAM1, FAS, and ULBP2 (Fig. 4D). Unexpectedly, the expression of a previously reported canonical marker of immunogenic cell death, calreticulin, was also enriched in the cellular senescence pathway of the Gene Ontology database (data not shown) [33]. 

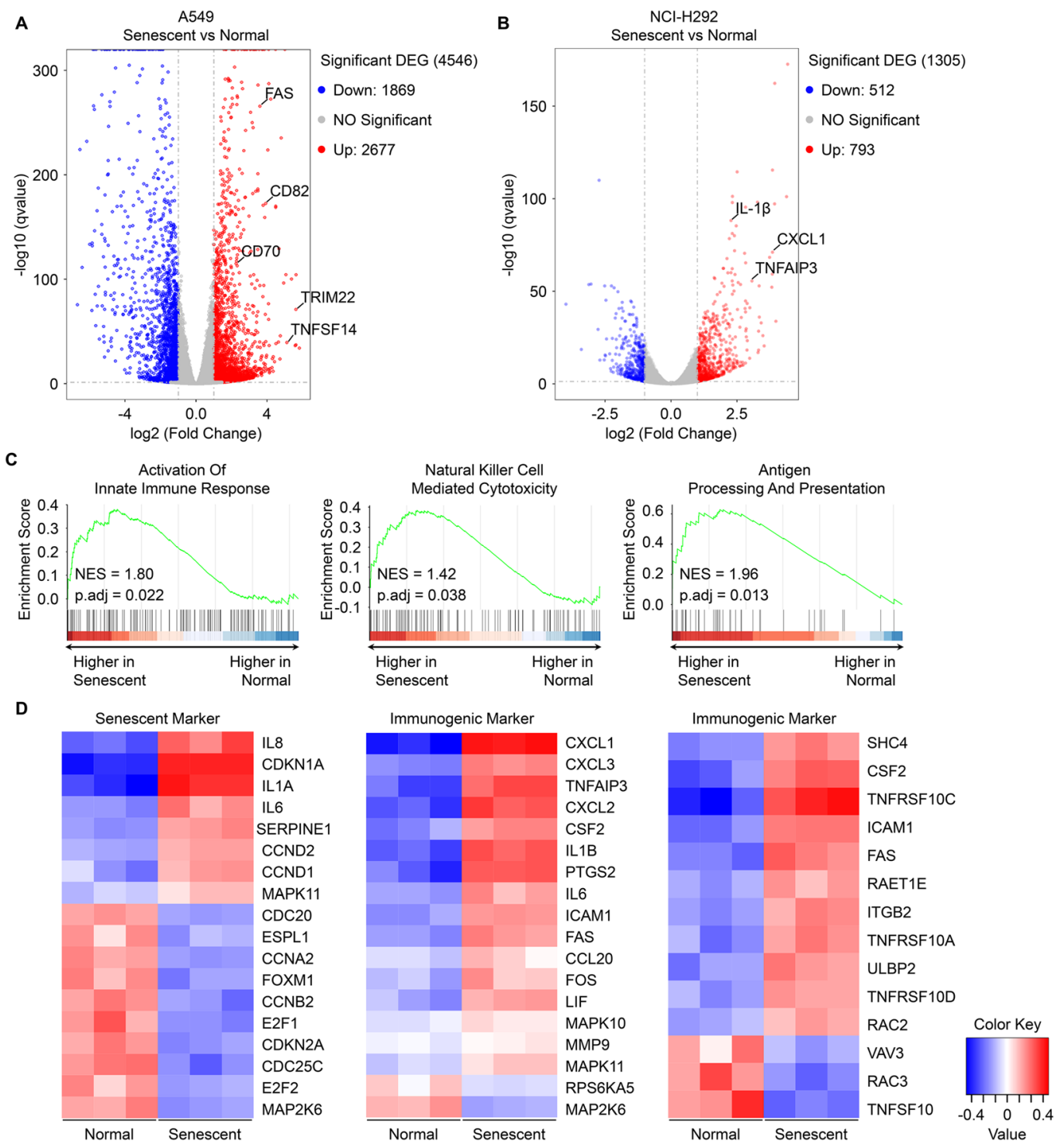

E

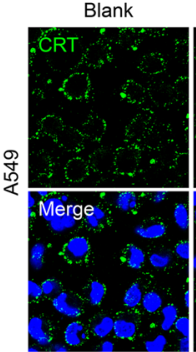

Blank

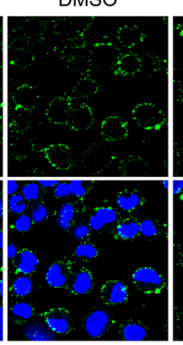

DMSO

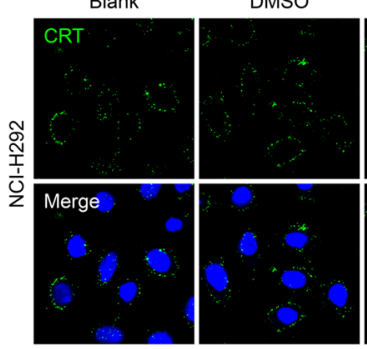

$50 \mathrm{nM}$ MTX

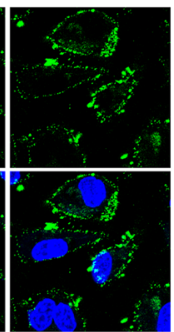

50 nM MTX

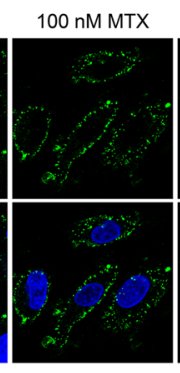

100 nM MTX

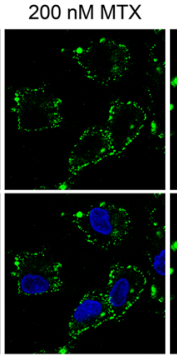

200 nM MTX

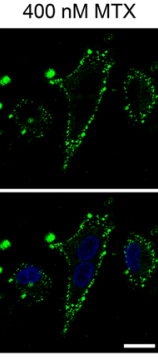

400 nM MTX

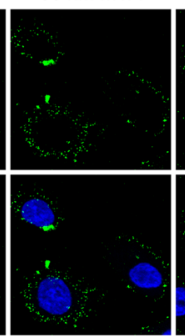

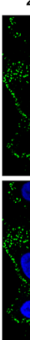

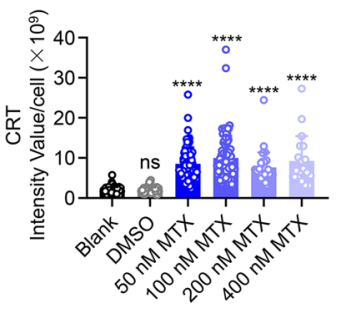

H

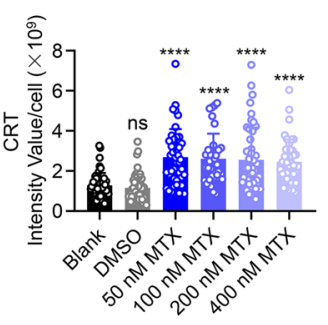


४Fig. 4 Senescent cells exhibit an immunogenic signature (A, B) Volcano plots of RNA-seq transcriptional profiles after treatment with $50 \mathrm{nM}$ mitoxantrone for $48 \mathrm{~h}$ in A549 cells (A) and NCI-H292 cells (B). Genes that show significantly different expressions are shown. C Significantly enriched immunogenic pathways according to gene set enrichment analysis comparing mitoxantrone-treated A549 cells versus normal A549 cells. D Expression of signature core cellular senescence genes and immunogenic genes in mitoxantrone-treated NCI-H292 cells versus normal NCI-H292 cells. E-H Confocal laser scanning microscopy of the expression of calreticulin on the surface of A549 cells (E) and NCI-H292 cell (G) treated with the indicated concentration of mitoxantrone. We calculated the intensity value of each A549 cells $(\mathbf{F})$ and NCI-H292 cell $(\mathbf{H})$. Scale bar $=20 \mu \mathrm{m}$

To confirm this observation, we measured the calreticulin expression on A549 cells and NCI-H292 cells after mitoxantrone treatment by immunofluorescence. Mitoxantrone treatment increased the level of cell-surface calreticulin markedly, which might help the translocation of LUNX and the increasing immunogenicity (Fig. 4E-H). These findings indicated that immunogenic chemotherapy treatmentinduced cellular senescence and that these senescent tumor cells exhibited an immunogenic signature.

\section{Immunogenic senescent cells are sensitive to LUNX-targeting therapy}

We employed RT-qPCR to ascertain if expression of known NKG2D ligands was up-regulated, as shown by transcription data (Fig. 4D). Human NKG2D ligands consist of the ULBP family, including ULBP1-6, MIC-A, and MIC-B [6] [35]. Of note, a more-than-twofold increase in the expression of ULBP2, ULBP5, and ULBP6 was observed, whereas the expression of ULBP1 and ULBP3 decreased. There was no significant difference in the expression of MIC-A and MIC-B after mitoxantrone treatment (Fig. 5A, B). Furthermore, flow cytometry revealed that the relative geometric mean fluorescence intensity of ULBP $2 / 5 / 6$ was much higher in mitoxantrone-induced senescent A549 cells compared with that in normal A549 cells (Fig. 5C, D). Similar results were observed in NCI-H292 cells (Figure S4A-D).

Having identified the increased expression of NK-cell activating ligands in senescent A549 cells, we hypothesized that senescent A549 cells might be more sensitive to NK cell-mediated killing [34]. Using real-time cytotoxicity analysis (RTCA) of normal cells alone or senescent A549 cells alone, we found that normal A549 cells showed exponential growth whereas senescent A549 cells barely proliferated at the indicated time points, which reflected the basic difference between normal cells and senescent cells (Fig. 5E). Upon co-culture with NK cells at different effect/target ratios, normal cells or senescent A549 cells were killed rapidly but showed no significant difference in cytotoxicity at the same E/T ratio (Fig. 5E, F).
Early reports suggested that NK cells specifically target tumor cells undergoing therapy-induced senescence in an NKG2D ligand-dependent manner, but this effect might not be true for mitoxantrone-induced senescent A549 cells [7]. Another important signature of senescent A549 cells and NCI-H292 cells demonstrated previously was the substantial expression of LUNX protein on cell membranes, which could be targeted as lung cancer-specific antigen by anti-LUNX antibody (Fig. 1A-D). Accordingly, we tested whether anti-LUNX antibody could promote NK cell-mediated cytotoxicity towards senescent A549 cells. RTCA data revealed that senescent A549 cells co-cultured with NK cells in the presence of anti-LUNX antibody showed a stronger killing efficiency than those co-cultured without anti-LUNX antibody after $24 \mathrm{~h}$. However, when using normal A549 cells, a significant difference in the normalized Cell Index was not found until $36 \mathrm{~h}$ (Fig. 5G, H). This result suggested that, compared with normal A549 cells, senescent A549 cells might respond more strongly to anti-LUNX antibody. Hence, we measured the ability of anti-LUNX antibody alone to suppress the survival of A549 cells.

Increasing concentrations of anti-LUNX antibody exhibited no or a moderately inhibitory effect upon normal A549 cells. However, senescent A549 cells showed much greater sensitivity to treatment with anti-LUNX antibody alone without NK cells, as shown by a significantly decreased normalized Cell Index, which was dependent upon the concentration (Fig. 5I, J). Although senescent NCI-H292 cells also up-regulated the expression of LUNX, increasing sensitivity to antibody treatment was not observed in these senescent cells. This result might have been because the unrestrained proliferation of these tumor cells left little time for the antibody to elicit its effect (Figure S4E, F). Taken together, these data provided evidence that senescent A549 cells expressing substantial LUNX expression on the cell membrane showed increasing antigenicity, and were sensitive to anti-LUNX antibody-mediated killing.

\section{Immunogenic senescence improves LUNX-targeting therapy in a model of lung cancer}

We wished to discover if the results mentioned above were translated in vivo. We conducted a study based on inhibition of tumor growth with a xenograft model using A549 cells. First, we injected (s.c.) normal A549 cells into immunedeficient nude mice. We treated these tumor-bearing mice with increasing doses of mitoxantrone. Two days later, we harvested the tumors for immunofluorescence-based measurement of LUNX expression (Fig. 6A-C). As expected, mitoxantrone treatment increased the cell surface expression of LUNX within the tumor bed in vivo. Then, we tested if a combination of mitoxantrone with an anti-LUNX antibody led to efficient tumor control. Co-treatment with 
A

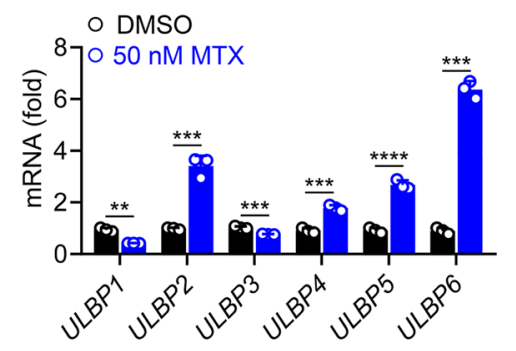

E

\section{E:T (NK: Normal A549)}

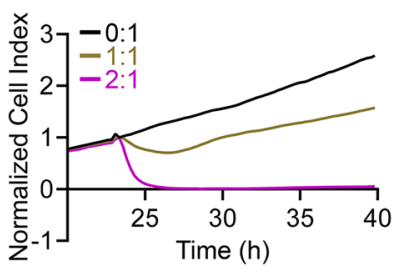

G

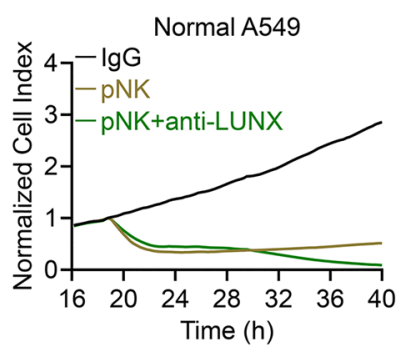

I

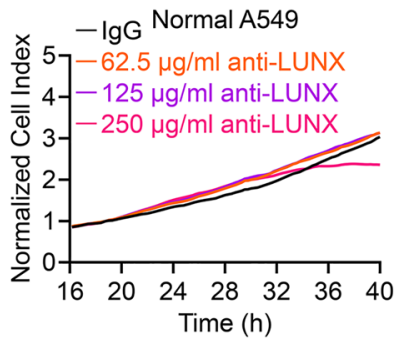

B

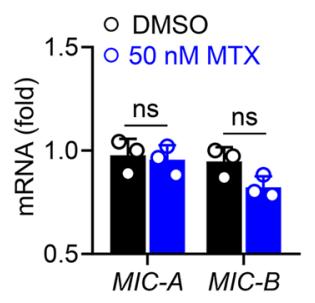

C

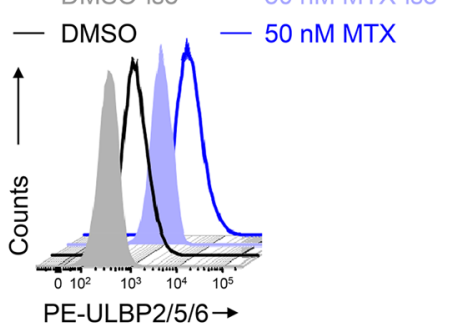

D

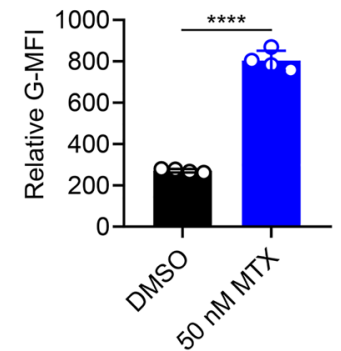

$\mathbf{F}$
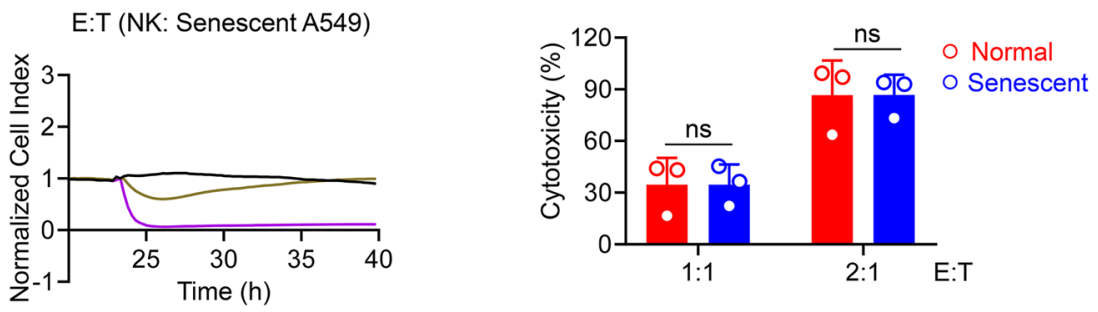

H
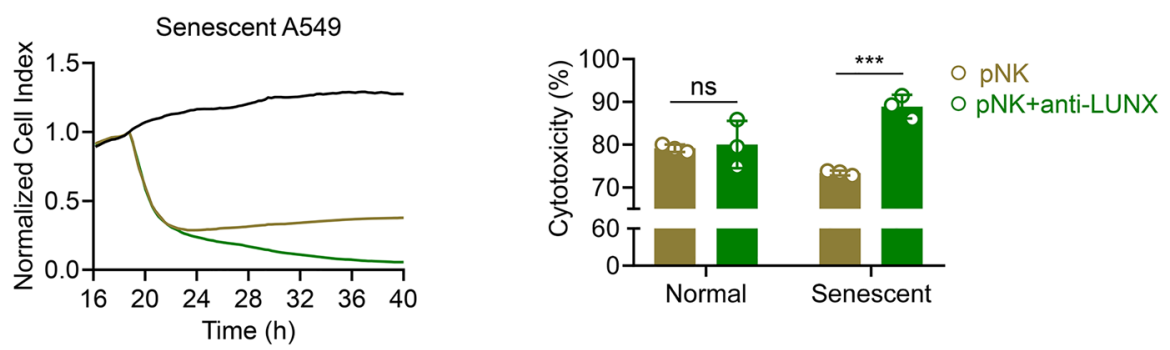

$\mathbf{J}$
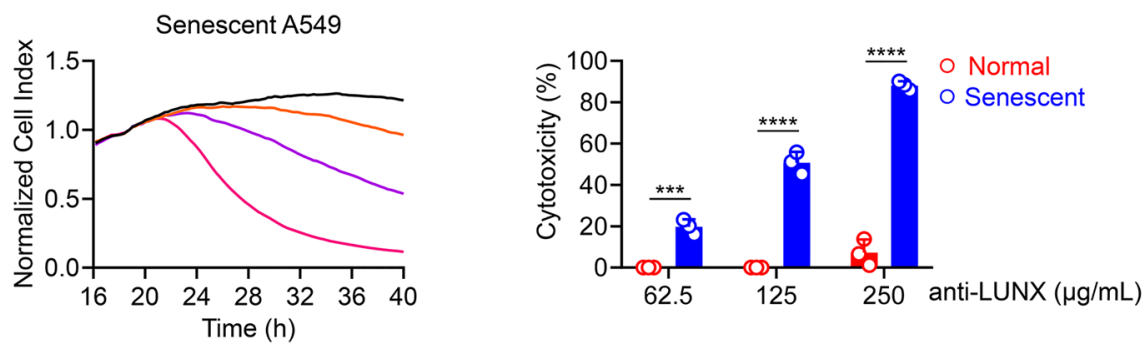

Fig. 5 Immunogenic senescent cells are more sensitive to LUNXtargeting therapy (A, B) RT-qPCR of the genes of NKG2D ligands in A549 cells treated with mitoxantrone or DMSO. C, D Flow cytometry showing ULBP2/5/6 expression in A549 cells treated with mitoxantrone or DMSO. We calculated the relative geometric mean fluorescence intensity of A549 cells treated with mitoxantrone or DMSO. E, F Real-time Cell Index measurement of normal or senescent (mitoxantrone-treated) A549 cells as target cells cultured with differ- ent ratios of effector NK cells. The relative cytotoxicity is shown in (F). G, H Real-time Cell Index measurement of normal or senescent A549 target cells cultured at a ratio 2:1 of effector NK cells with or without $250 \mu \mathrm{g} / \mathrm{mL}$ anti-LUNX antibody. The relative cytotoxicity is shown in (H). I, J Real-time Cell Index measurement of normal or senescent target A549 cells cultured in the presence of different concentrations of anti-LUNX antibody alone. The relative cytotoxicity is shown in $(\mathrm{J})$

with the group treated with mitoxantrone alone (Fig. 6D, E). These results suggested that sequential combination of mitoxantrone and anti-LUNX antibody might increase 
the expression of LUNX and kill LUNX-expressing cells, respectively, and finally lead to reduced tumor progression.

Next, we wondered whether normal cells and senescent A549 cells showed the same sensitivity to an anti-LUNX antibody in vivo. NOD.SCID $\gamma c$-deficient mice were inoculated (s.c.) with normal cells or senescent A549 cells via the subcutaneous (Fig. 6F, G) or intravenous (Fig. 6H, I) route. Notably, normal A549 cells proliferated much faster than senescent A549 cells in vivo, and the latter showed negligible growth irrespective of where the tumor cells were inoculated (Fig. 6G, I). This difference was unsurprising because senescent A549 cells barely proliferated in vitro. Furthermore, senescent A549 cells were much more sensitive to anti-LUNX antibody because mice bearing this type of tumor cell had a lower tumor burden compared with mice in the IgG group (Fig. 6G, I). Live images of mice also showed a much lower tumor burden in mice bearing senescent A549 cells and then treated with anti-LUNX antibody (Fig. 6J). To further prove the importance of NK cells-mediating-ADCC in tumor rejection, we subcutaneously inoculated normal or senescent A549 cells with or without human PBMC derived NK cells in the presence of anti-LUNX antibody or human IgG. For both normal and senescent A549 cells, inoculation with anti-LUNX antibody in the presence of NK cells significantly reduced the tumor volume compared to inoculation with anti-LUNX antibody alone, which suggested that ADCC-mediated by NK cells also contributed to tumor rejection in vivo (Fig. 6K, L). As shown in Fig. 6K, L, senescent A549 cells were much more sensitive to anti-LUNX antibody as they showed lower tumor volume when inoculated with anti-LUNX antibody compared to inoculation with NK cells, which were not seen in normal A549 cells.

Our aforementioned results (Figure S1C, 1D) suggested that gemcitabine could also induce the translocation of LUNX. Accordingly, we tested the anti-tumor ability of gemcitabine combined with anti-LUNX antibody in vivo. As expected, gemcitabine also showed an immunogenic senescence effect because anti-LUNX antibody-treated mice showed a lower tumor burden and slower tumor progression (Figure S5A-C). Taken together, these results indicated that immunogenic drugs that promoted LUNX shuttling might improve LUNX-targeting therapy and inhibit tumor growth.

\section{Discussion}

We propose that induction of immunogenic senescence of tumor cells is a promising approach for cancer immunotherapy. Tumor cells develop multiple adaptations to the immune system to escape recognition, but their immunogenicity can be strengthened through the induction of senescence [28]. Senescence has been thought to serve as a tumor-suppressive mechanism $[18,26]$. Kang and colleagues showed that senescence surveillance prevents the expansion of premalignant cells in hepatocellular carcinoma [24]. Likewise, senescent tumor cells strongly activate NK cells through NKG2D or other activating receptors and, finally, are eliminated by the immune system in multiple myeloma [7, 39]. Recently, Amor and colleagues identified that urokinase-type plasminogen activator receptor-specific CAR T cells can efficiently ablate senescent cells in senescence-associated diseases not limited to tumors (e.g., liver fibrosis) [1]. Thus, senescent tumor cells coincide with a more immunogenic phenotype than their normal-cell counterparts and are distinguished by much higher expression of common activating ligands and specific tumor antigens.

We demonstrated that LUNX is a lung cancer targetable tumor antigen during immunogenic senescence. Targeting LUNX via anti-LUNX antibody suppressed the survival of senescent tumor cells in vitro and in vivo. We showed that LUNX expression on the cell surface can be increased significantly by immunogenic chemotherapy using mitoxantrone, which induces a senescence phenotype instead of immunogenic cell death as reported previously $[30,40]$. This difference in data may have resulted from the different doses used in our study. Tumor cells are not killed directly by a sublethal dose of mitoxantrone treatment, but most of these cells enter "premature senescence", which is strengthened further even after drug withdrawal. Attempting to survive under this drug-induced stress, tumor cells express more LUNX on their plasma membrane, the overexpression of which we showed previously to promote the migration and proliferation of lung cancer cells [43]. Targeting surface LUNX via anti-LUNX antibody at this time more efficiently suppresses the survival of these LUNX-high-expressing senescent tumor cells. Meanwhile, these cells also exhibit a stronger potential to activate the immune system with the expression of NKG2D ligands as well as the adjuvant molecule calreticulin [31,35]. Though these senescent tumor cells survive sublethal stress, they remain in a highly immunogenic state with strong antigenicity and adjuvanticity.

Reports have suggested that senescent cells show high expression of NKG2D ligands (e.g., MIC-A and ULBP2) and are sensitive to NKG2D ligand-dependent killing [21, 35]. This phenomenon may be dependent upon the intrinsic low expression of these activating ligands. We also detected increased expression of these ligands on senescent tumor cells. However, there was no significant difference in the sensitivity to NK cell-mediated killing because these tumor cells had a higher background expression than that of normal cells. Our recent report demonstrated that low-dose gemcitabine treatment could enhance the immunogenicity of lung 
A

Normal A549 cells inoculation (s.c.)

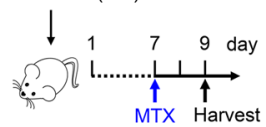

B
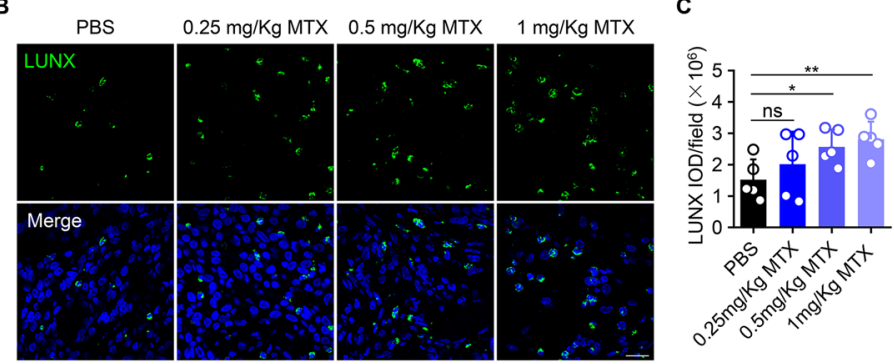

E

Normal A549 cells

inoculation (s.c.)

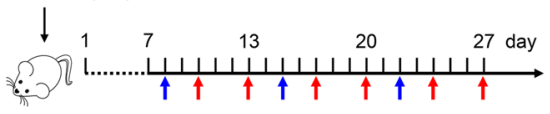
Grp 1:MTX+lgG

Grp 2:MTX+anti-LUNX

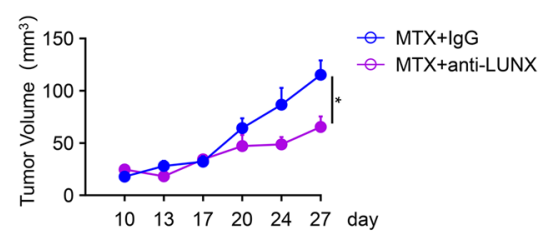

Normal/Senescent

A549 cells

inoculation (s.c.)

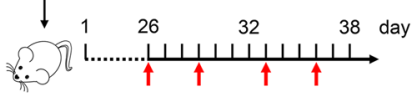

Grp 1:Normal+lgG Grp 3:Senescent+lgG

Grp 2:Normal+anti-LUNX Grp 4:Senescent+anti-LUNX

G

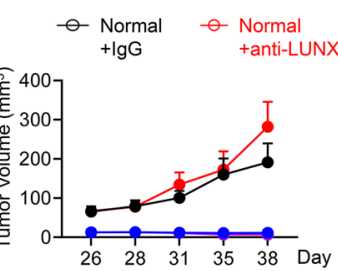

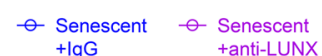

Normal/Senescent

A549 cells

inoculation (i.v.)

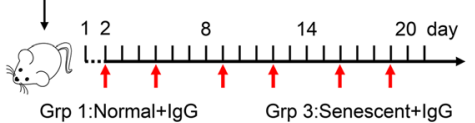

Grp 1:Normal+lgG Grp 3.Senescent+lgG

Grp 2:Normal+anti-LUNX Grp 4:Senescent+anti-LUNX
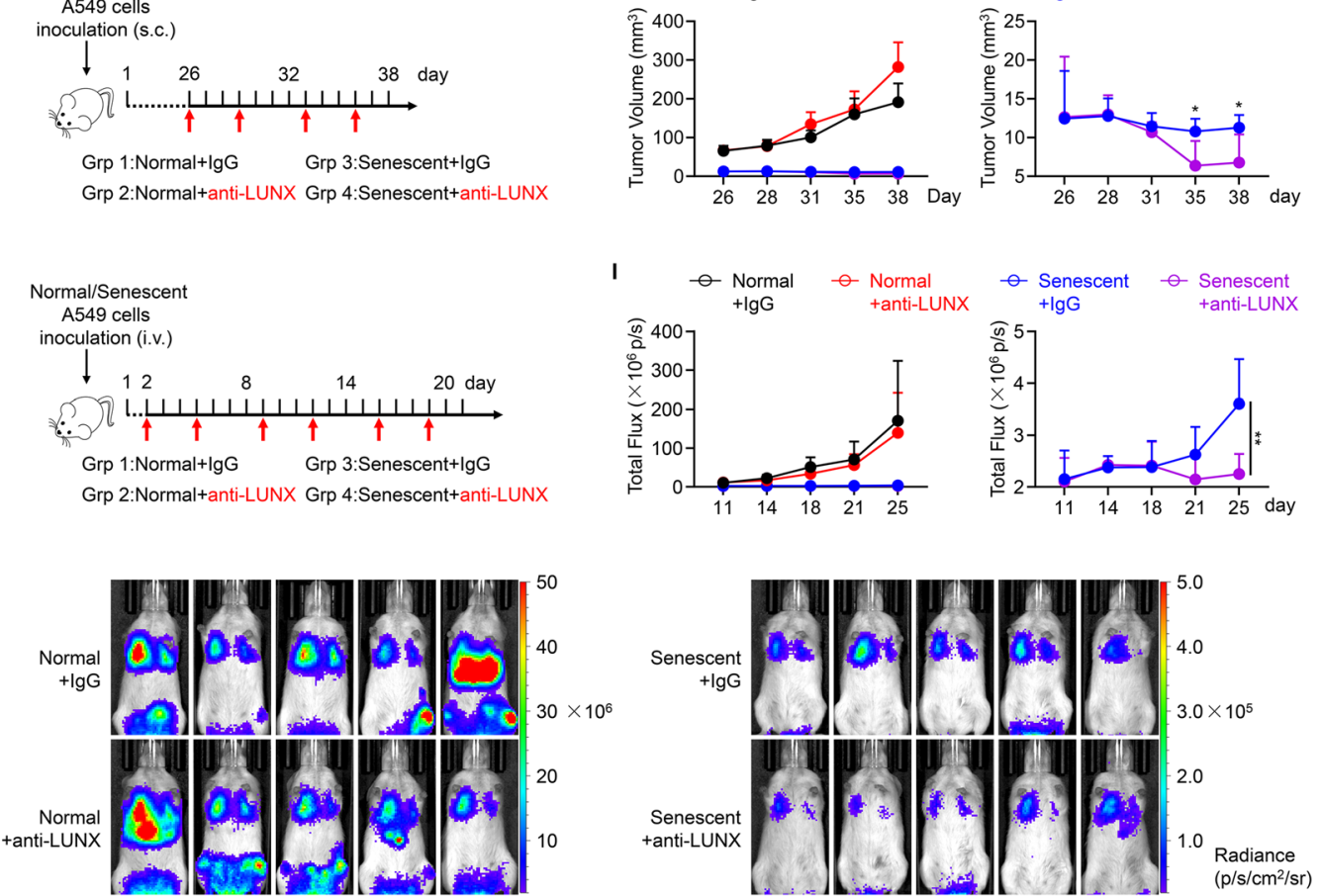
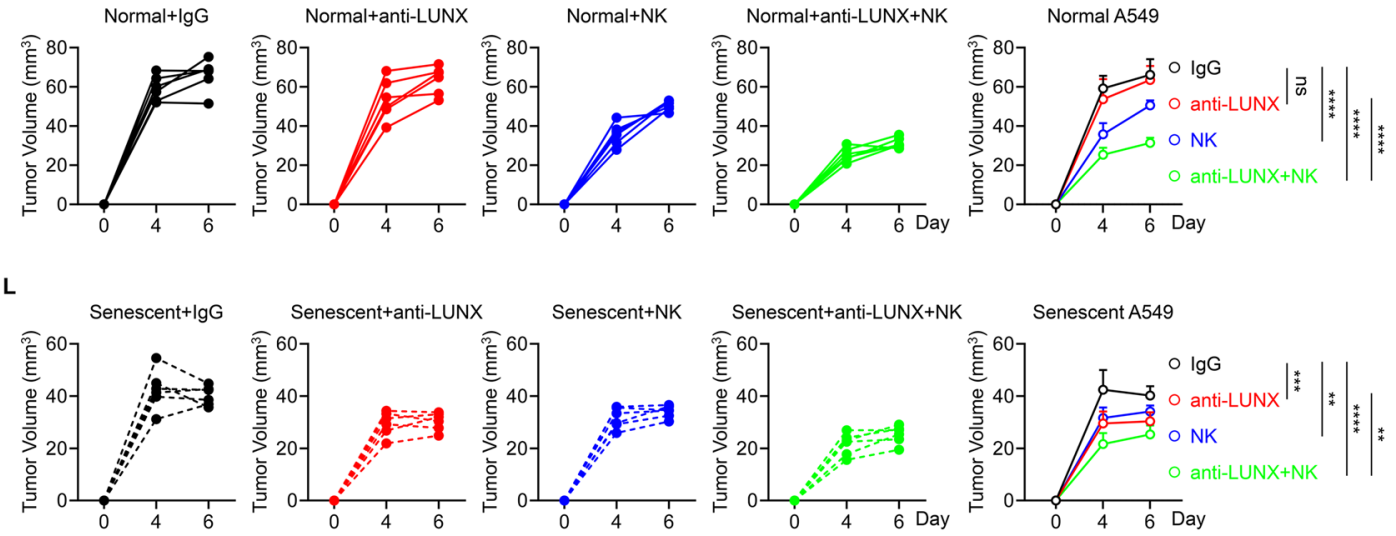
4Fig. 6 Immunogenic senescence improves LUNX-targeting therapy in a model of lung cancer (A-C) Mitoxantrone treatment improved LUNX expression in vivo. A Experimental scheme. A549 cells were injected (s.c.) and then mice were treated with the indicated concentration of mitoxantrone. Two days later, tumors were harvested for immunofluorescence detection of LUNX expression. Representative images are shown $(\mathbf{B})$ and we calculated the intensity value of each field of LUNX (C). D, E Combination of mitoxantrone and anti-LUNX antibody ( $80 \mathrm{mg} / \mathrm{kg}$ ) suppressed tumor growth. Schematic representation of the experimental protocol (D). Tumorgrowth curves showed the mean tumor volume $\left(\mathrm{mm}^{3}\right) \pm \mathrm{SD}(n=5)$. F-J Immunogenic senescent A549 cells are sensitive to anti-LUNX antibody therapy. Schematic representation of the experimental protocol; the dose of anti-LUNX used is $80 \mathrm{mg} / \mathrm{kg}(\mathbf{F}, \mathbf{H})$. Tumorgrowth curves showing the mean tumor volume $\left(\mathrm{mm}^{3}\right) \pm \mathrm{SD}(n=6)$ (G) or the total flux $(\mathrm{p} / \mathrm{s}) \pm \mathrm{SD}(n=5)(\mathrm{I})$. Representative image of tumor burden in each mouse was shown in $(\mathbf{j})$. K, $\mathbf{L}$ ADCC-mediated by NK cells suppressed tumor growth. $2 \times 10^{6}$ normal $(\mathbf{K})$ or senescent (L) A549 cells were inoculated subcutaneously with or without $1 \times 10^{6}$ human PBMC derived NK cells in the presence of $500 \mu \mathrm{g} /$ $\mathrm{mL}$ anti-LUNX antibody or human IgG. Tumor-growth curves in the right showing the mean tumor volume $\left(\mathrm{mm}^{3}\right) \pm \mathrm{SD}(n=6)$

cancer cells [41]. Gemcitabine treatment also increased the expression of LUNX on cell surfaces in vitro and suppressed tumor growth in vivo, so additional studies will be needed to accelerate the translation from basic science research to the clinic. Our findings suggest that the induction of immunogenic senescence using FDA-approved drugs in combination with anti-LUNX antibody might provide a new strategy for NSCLC treatment.

Supplementary Information The online version contains supplementary material available at https://doi.org/10.1007/s00262-021-03077-1.

Acknowledgments I am indebted most sincerely to Siao Chen for her company and encouragement during such exacting work. When the work is published, will you marry me?

Author contributions $\mathrm{HW}, \mathrm{BF}, \mathrm{XZ}$, and DJ conceived and conducted the project. HW supervised the project. DJ, XZ, and HW wrote the manuscript. DJ carried out the experiments and data analyses. XD contributed to cell-culture experiments. DW and $\mathrm{ZH}$ contributed to the drug evaluation and animal models, respectively. RS and ZT interpreted the data.

Funding This work was supported by the Natural Science Foundation of China (81872318), Strategic Priority Research Program of the Chinese Academy of Sciences (XDB39020700 to B.F.), and Youth Innovation Promotion Association of Chinese Academy of Sciences (2019442)

Availability of data and material All data are available.

\section{Declarations}

Conflict of interest The authors declare no potential conflicts of interest.

Open Access This article is licensed under a Creative Commons Attribution 4.0 International License, which permits use, sharing, adaptation, distribution and reproduction in any medium or format, as long as you give appropriate credit to the original author(s) and the source, provide a link to the Creative Commons licence, and indicate if changes were made. The images or other third party material in this article are included in the article's Creative Commons licence, unless indicated otherwise in a credit line to the material. If material is not included in the article's Creative Commons licence and your intended use is not permitted by statutory regulation or exceeds the permitted use, you will need to obtain permission directly from the copyright holder. To view a copy of this licence, visit http://creativecommons. org/licenses/by/4.0/.

\section{References}

1. Amor C, Feucht J, Leibold J, Ho Y-J, Zhu C, Alonso-Curbelo D, Mansilla-Soto J, Boyer JA, Li X, Giavridis T, Kulick A, Houlihan S, Peerschke E, Friedman SL, Ponomarev V, Piersigilli A, Sadelain M, Lowe SW (2020) Senolytic CAR T cells reverse senescence-associated pathologies. Nature 538:127

2. Angell HK, Tosolini M, Mlecnik B, Bindea G, Fredriksen T, Lafontaine L, Waldner M, Pagès F, Valge-Archer V, Galon J (2013) The impact of cellular senescence and DNA damage on colorectal tumour progression. J Immunother Cancer 1:P144

3. Bingle L, Barnes FA, Cross SS, Rassl D, Wallace WA, Campos MA, Bingle CD (2007) Differential epithelial expression of the putative innate immune molecule SPLUNC1 in cystic fibrosis. Respir Res 8:79

4. Bingle L, Bingle CD (2011) Distribution of human PLUNC/ BPI fold-containing (BPIF) proteins. Biochem Soc Trans 39:1023-1027

5. Bingle L, Cross SS, High AS, Wallace WA, Devine DA, Havard S, Campos MA, Bingle CD (2005) SPLUNC1 (PLUNC) is expressed in glandular tissues of the respiratory tract and in lung tumours with a glandular phenotype. J Pathol 205:491-497

6. Bonnafous C, Peri V, Trichard S, Perrot I, Cornen S, Thielens A, Breso V, Morel Y, Rossi B, Paturel C, Gauthier L, Bléry M (2013) Targeting MICA with therapeutic antibodies for the treatment of cancer. J Immunother Cancer 1:P41

7. Borrelli C, Ricci B, Vulpis E, Fionda C, Ricciardi MR, Petrucci MT, Masuelli L, Peri A, Cippitelli M, Zingoni A, Santoni A, Soriani A (2018) Drug-induced senescent multiple myeloma cells elicit NK cell proliferation by direct or exosome-mediated IL15 $<$ em $>$ Trans $<$ /em $>$-Presentation. Cancer Immunol Res 6:860

8. Calcinotto A, Kohli J, Zagato E, Pellegrini L, Demaria M, Alimonti A (2019) Cellular senescence: aging, cancer, and injury. Physiol Rev 99:1047-1078

9. Casella G, Munk R, Kim KM, Piao Y, De S, Abdelmohsen K, Gorospe M (2019) Transcriptome signature of cellular senescence. Nucleic Acids Res 47:7294-7305

10. Cheng M, Chen Y, Yu X, Tian Z, Wei H (2008) Diagnostic utility of LunX mRNA in peripheral blood and pleural fluid in patients with primary non-small cell lung cancer. BMC Cancer 8:156

11. Chicas A, Wang X, Zhang C, McCurrach M, Zhao Z, Mert O, Dickins RA, Narita M, Zhang M, Lowe SW (2010) Dissecting the unique role of the retinoblastoma tumor suppressor during cellular senescence. Cancer Cell 17:376-387

12. Chien Y, Scuoppo C, Wang X, Fang X, Balgley B, Bolden JE, Premsrirut P, Luo W, Chicas A, Lee CS, Kogan SC, Lowe SW (2011) Control of the senescence-associated secretory phenotype by NF- $\mathrm{\kappa B}$ promotes senescence and enhances chemosensitivity. Genes Dev 25:2125-2136 
13. Di Y-P, Harper R, Zhao Y, Pahlavan N, Finkbeiner W, Wu R (2003) Molecular cloning and characterization of spurt, a human novel gene that is retinoic acid-inducible and encodes a secretory protein specific in upper respiratory tracts*. J Biol Chem 278:1165-1173

14. Evison BJ, Sleebs BE, Watson KG, Phillips DR, Cutts SM (2016) Mitoxantrone, more than just another topoisomerase II poison. Med Res Rev 36:248-299

15. Faget DV, Ren Q, Stewart SA (2019) Unmasking senescence: context-dependent effects of SASP in cancer. Nat Rev Cancer 19:439-453

16. Falciola L, Spada F, Calogero S, Längst G, Voit R, Grummt I, Bianchi ME (1997) High mobility group 1 protein is not stably associated with the chromosomes of somatic cells. J Cell Biol 137:19-26

17. Galluzzi L, Buqué A, Kepp O, Zitvogel L, Kroemer G (2017) Immunogenic cell death in cancer and infectious disease. Nat Rev Immunol 17:97-111

18. Gorgoulis V, Adams PD, Alimonti A, Bennett DC, Bischof O, Bishop C, Campisi J, Collado M, Evangelou K, Ferbeyre G, Gil J, Hara E, Krizhanovsky V, Jurk D, Maier AB, Narita M, Niedernhofer L, Passos JF, Robbins PD, Schmitt CA, Sedivy J, Vougas K, von Zglinicki T, Zhou D, Serrano M, Demaria M (2019) Cellular senescence: defining a path forward. Cell 179:813-827

19. Hu G, Liu Y, Li H, Zhao D, Yang L, Shen J, Hong X, Cao X, Wang Q (2010) Adenovirus-mediated LIGHT gene modification in murine B-cell lymphoma elicits a potent antitumor effect. Cell Mol Immunol 7:296-305

20. Hu Z, Zheng X, Jiao D, Zhou Y, Sun R, Wang B, Tian Z, Wei H (2020) LunX-CAR T cells as a targeted therapy for non-small cell lung cancer. Mol Therapy Oncolyt 17:361-370

21. Iannello A, Thompson TW, Ardolino M, Lowe SW, Raulet DH (2013) p53-dependent chemokine production by senescent tumor cells supports NKG2D-dependent tumor elimination by natural killer cells. J Exp Med 210:2057-2069

22. Iwao K, Watanabe T, Fujiwara Y, Takami K, Kodama K, Higashiyama M, Yokouchi H, Ozaki K, Monden M, Tanigami A (2001) Isolation of a novel human lung-specific gene, LUNX, a potential molecular marker for detection of micrometastasis in non-smallcell lung cancer. Int J Cancer 91:433-437

23. Jacobs J, Deschoolmeester V, Zwaenepoel K, Rolfo C, Silence K, Rottey S, Lardon F, Smits E, Pauwels P (2015) CD70: an emerging target in cancer immunotherapy. Pharmacol Ther 155:1-10

24. Kang T-W, Yevsa T, Woller N, Hoenicke L, Wuestefeld T, Dauch D, Hohmeyer A, Gereke M, Rudalska R, Potapova A, Iken M, Vucur M, Weiss S, Heikenwalder M, Khan S, Gil J, Bruder D, Manns M, Schirmacher P, Tacke F, Ott M, Luedde T, Longerich T, Kubicka S, Zender L (2011) Senescence surveillance of premalignant hepatocytes limits liver cancer development. Nature 479:547

25. Kroemer G, Galluzzi L, Kepp O, Zitvogel L (2013) Immunogenic cell death in cancer therapy. Annu Rev Immunol 31:51-72

26. Lee S, Schmitt CA (2019) The dynamic nature of senescence in cancer. Nat Cell Biol 21:94-101

27. Lindahl M, Ståhlbom B, Tagesson C (2001) Identification of a new potential airway irritation marker, palate lung nasal epithelial clone protein, in human nasal lavage fluid with two-dimensional electrophoresis and matrix-assisted laser desorption/ionizationtime of flight. Electrophoresis 22:1795-1800

28. Malmberg K-J, Ljunggren H-G (2006) Escape from immune- and nonimmune-mediated tumor surveillance. Semin Cancer Biol $16: 16-31$

29. Narita M, Nuñez S, Heard E, Narita M, Lin AW, Hearn SA, Spector DL, Hannon GJ, Lowe SW (2003) Rb-mediated heterochromatin formation and silencing of E2F target genes during cellular senescence. Cell 113:703-716
30. Obeid M, Tesniere A, Ghiringhelli F, Fimia GM, Apetoh L, Perfettini J-L, Castedo M, Mignot G, Panaretakis T, Casares N, Métivier D, Larochette N, van Endert P, Ciccosanti F, Piacentini M, Zitvogel L, Kroemer G (2006) Calreticulin exposure dictates the immunogenicity of cancer cell death. Nat Med 13:54

31. Obeid M, Tesniere A, Panaretakis T, Tufi R, Joza N, Van Endert P, Ghiringhelli F, Apetoh L, Chaput N, Flament C, Ullrich E, De Botton S, Zitvogel L, Kroemer G (2007) Ecto-calreticulin in immunogenic chemotherapy. Immunol Rev 220:22-34

32. Pfirschke C, Engblom C, Rickelt S, Cortez-Retamozo V, Garris C, Pucci F, Yamazaki T, Poirier-Colame V, Newton A, Redouane Y, Lin Y-J, Wojtkiewicz G, Iwamoto Y, Mino-Kenudson M, Huynh TG, Hynes RO, Freeman GJ, Kroemer G, Zitvogel L, Weissleder R, Pittet MJ (2016) Immunogenic chemotherapy sensitizes tumors to checkpoint blockade therapy. Immunity 44:343-354

33. Raghavan M, Wijeyesakere SJ, Peters LR, Del Cid N (2013) Calreticulin in the immune system: ins and outs. Trends Immunol 34:13-21

34. Ruscetti M, Leibold J, Bott MJ, Fennell M, Kulick A, Salgado NR, Chen C-C, Ho Y-J, Sanchez-Rivera FJ, Feucht J, Baslan T, Tian S, Chen H-A, Romesser PB, Poirier JT, Rudin CM, de Stanchina E, Manchado E, Sherr CJ, Lowe SW (2018) NK cell-mediated cytotoxicity contributes to tumor control by a cytostatic drug combination. Science 362:1416-1422

35. Sagiv A, Burton DGA, Moshayev Z, Vadai E, Wensveen F, BenDor S, Golani O, Polic B, Krizhanovsky V (2016) NKG2D ligands mediate immunosurveillance of senescent cells. Aging 8:328-344

36. Samstein RM, Lee C-H, Shoushtari AN, Hellmann MD, Shen R, Janjigian YY, Barron DA, Zehir A, Jordan EJ, Omuro A, Kaley TJ, Kendall SM, Motzer RJ, Hakimi AA, Voss MH, Russo P, Rosenberg J, Iyer G, Bochner BH, Bajorin DF, Al-Ahmadie HA, Chaft JE, Rudin CM, Riely GJ, Baxi S, Ho AL, Wong RJ, Pfister DG, Wolchok JD, Barker CA, Gutin PH, Brennan CW, Tabar V, Mellinghoff IK, DeAngelis LM, Ariyan CE, Lee N, Tap WD, Gounder MM, D'Angelo SP, Saltz L, Stadler ZK, Scher HI, Baselga J, Razavi P, Klebanoff CA, Yaeger R, Segal NH, Ku GY, DeMatteo RP, Ladanyi M, Rizvi NA, Berger MF, Riaz N, Solit DB, Chan TA, Morris LGT (2019) Tumor mutational load predicts survival after immunotherapy across multiple cancer types. Nat Genet 51:202-206

37. Seifrtova M, Havelek R, Soukup T, Filipova A, Mokry J, Rezacova M (2013) Mitoxantrone ability to induce premature senescence in human dental pulp stem cells and human dermal fibroblasts. J Physiol Pharmacol 64(2):255-266 PMID: 23756401

38. Smith AA, Hodge J, Garnett C, Farsaci B, Palena C, Tsang K-Y, Ferrone S, Gamiero S (2013) Chemotherapy-induced immunogenic modulation of tumor cells enhances killing by cytotoxic $\mathrm{T}$ lymphocytes and is distinct from immunogenic cell death. $\mathbf{J}$ Immunother Cancer 1:P91

39. Soriani A, Zingoni A, Cerboni C, Iannitto ML, Ricciardi MR, Di Gialleonardo V, Cippitelli M, Fionda C, Petrucci MT, Guarini A, Foà R, Santoni A (2009) ATM-ATR-dependent up-regulation of DNAM-1 and NKG2D ligands on multiple myeloma cells by therapeutic agents results in enhanced NK-cell susceptibility and is associated with a senescent phenotype. Blood 113:3503

40. Yang H, Xia L, Chen J, Zhang S, Martin V, Li Q, Lin S, Chen J, Calmette J, Lu M, Fu L, Yang J, Pan Z, Yu K, He J, Morand E, Schlecht-Louf G, Krzysiek R, Zitvogel L, Kang B, Zhang Z, Leader A, Zhou P, Lanfumey L, Shi M, Kroemer G, Ma Y (2019) Stress-glucocorticoid-TSC22D3 axis compromises therapyinduced antitumor immunity. Nat Med 25:1428-1441

41. Zhang X, Wang D, Li Z, Jiao D, Jin L, Cong J, Zheng X, Xu L (2020) Low-dose gemcitabine treatment enhances immunogenicity and natural killer cell-driven tumor immunity in lung cancer. Front Immunol. https://doi.org/10.3389/fimmu.2020.00331 
42. Zheng X, Cheng M, Fu B, Fan X, Wang Q, Yu X, Sun R, Tian Z, Wei H (2015) Targeting LUNX inhibits non-small cell lung cancer growth and metastasis. Can Res 75:1080

43. Zheng X, Tian Z, Wei H (2015) Lung specific $X$ protein as a novel therapeutic target for lung cancer. OncoImmunology 4:e1052931
Publisher's Note Springer Nature remains neutral with regard to jurisdictional claims in published maps and institutional affiliations. 